\title{
Fluorescent In Situ Hybridization 1p/19q Deletion/Imbalance Analysis of Low-Grade and Atypical Meningiomas
}

\author{
Toru NAgAsaKa, Masaharu Gunji*, Noboru HOSOKAI**, Kumiko HaYASHI**, \\ Masahiko FUjINO*, Hiroshi IKEDA, Masafumi ITO*, and Suguru INAO \\ Departments of Neurosurgery and *Pathology, \\ Japanese Red Cross Nagoya Daiichi Hospital, Nagoya, Aichi; \\ **Chromosome Testing Group, Molecular Genetic Testing Department, \\ Clinical Testing Center, Mitsubishi Chemical Medience, Inc., Tokyo
}

\begin{abstract}
The chromosomal 1p/19q state was analyzed in 16 low-grade meningiomas and 7 atypical meningiomas using fluorescent in situ hybridization (FISH) analysis. Chromosome 1p aberrations were observed in all atypical meningiomas, but in only one low-grade meningioma. Atypical meningiomas showed 19q deletion or imbalance, suggesting chromosomal instability of 19q. A small group of low-grade meningioma showed 19q aberrations. FISH 1p/19q deletion/imbalance analysis is a sensitive method for detecting chromosome aberrations of meningiomas and provides useful information for grading of meningiomas. Patients with low-grade meningioma with chromosomal instability of $1 \mathrm{p} / 19 \mathrm{q}$ should be followed up carefully. Assessment of the chromosomal state by FISH might be of crucial importance in the clinical management of meningiomas.
\end{abstract}

Key words: meningioma, fluorescent in situ hybridization, chromosome 1p/19q, chromosomal instability

\section{Introduction}

Meningiomas are common intracranial tumors arising from arachnoidal cells. Most meningiomas are benign (World Health Organization [WHO] grade I), but atypical meningiomas (WHO grade II) constitute between $4.7 \%$ and $7.2 \%$ of meningiomas, and anaplastic meningiomas (WHO grade III) account for $1.0-2.8 \%{ }^{11)}$ Both atypical and anaplastic meningiomas demonstrate histological and clinical features suggesting aggressive potential, and show a tendency for tumor recurrence, even after complete resection. Histological findings, such as increased cellularity, uninterrupted patternless growth, and mitotic figures may be helpful, but these subtle differences may not be readily apparent on routine hematoxylin-eosin staining, and may require measurement of MIB-1 labeling index to assess the proliferative activity. High MIB-1 labeling index is considered to be closely correlated with the histolog- ical grading of malignancy. The WHO classification of atypical meningioma requires increased mitotic activity of 4 or more mitoses per 10 high-power fields. ${ }^{10)}$ However, the correct cutoff value for these continuous variables is difficult to establish. Histological grades and MIB-1 labeling index have a fairly good correlation, but MIB-1 labeling index shows significant overlap between benign, atypical, and anaplastic meningiomas. ${ }^{11)}$ Therefore, these diagnostic markers of proliferation have limitations, and there is a need for a more precise, efficacious, and objective approach to the diagnosis and grading of meningiomas. Genetic characterization is another possible alternative for grading of meningiomas. ${ }^{2,16,18-20)}$

The present study explored the potential diagnostic utility of genetic alterations by comparing the histological features and chromosomal states in a series of meningiomas using fluorescent in situ hybridization (FISH).

Received January 21, 2008; Accepted February 25, 2009 
Table 1 Cases of low-grade and atypical meningiomas

\begin{tabular}{|c|c|c|c|c|c|c|c|c|c|c|c|}
\hline \multirow{2}{*}{$\begin{array}{l}\text { Case } \\
\text { No. }\end{array}$} & \multirow{2}{*}{$\begin{array}{c}\text { Age } \\
\text { (yrs)/ } \\
\text { Sex }\end{array}$} & \multirow[b]{2}{*}{ Location } & \multirow[b]{2}{*}{ Subtype } & \multirow{2}{*}{$\begin{array}{l}\text { WHO } \\
\text { grade }\end{array}$} & \multirow{2}{*}{$\begin{array}{c}\text { MIB-1 } \\
\text { LI } \\
(\%)\end{array}$} & \multicolumn{2}{|c|}{ FISH diagnosis } & \multirow{2}{*}{$\begin{array}{c}1 \mathrm{p} \\
\text { Normal } \\
(\%)\end{array}$} & \multirow{2}{*}{$\begin{array}{l}\text { 1p Abnor- } \\
\text { mality } \\
\text { (total, \%) }\end{array}$} & \multirow{2}{*}{$\begin{array}{c}19 q \\
\text { Normal } \\
(\%)\end{array}$} & \multirow{2}{*}{$\begin{array}{l}\text { 19q Abnor- } \\
\text { mality } \\
\text { (total, \%) }\end{array}$} \\
\hline & & & & & & FISH 1p & FISH 19q & & & & \\
\hline 1 & $42 / \mathrm{M}$ & $\begin{array}{l}\text { olfactory } \\
\text { groove }\end{array}$ & trans & I & 0.2 & normal & normal & 96.2 & 3.8 & 92.6 & 7.4 \\
\hline 2 & $62 / \mathrm{M}$ & $\begin{array}{l}\text { jugular } \\
\text { foramen }\end{array}$ & men & I & 1.5 & normal & normal & 97.3 & 2.7 & 97.7 & 2.3 \\
\hline 3 & $69 / \mathrm{F}$ & suprasellar & men & I & 0.6 & normal & normal & 90.1 & 9.9 & 92.6 & 7.4 \\
\hline 4 & $71 / \mathrm{F}$ & parasagittal & trans & I & 0.8 & normal & mono. & 89.9 & 10.1 & 44.5 & 55.5 \\
\hline 5 & $69 / \mathrm{F}$ & convexity & fibrous & I & 0.1 & normal & normal & 92.1 & 7.9 & 90.0 & 10.0 \\
\hline 6 & $72 / \mathrm{F}$ & convexity & angio & I & 0.1 & normal & normal & 98.5 & 1.5 & 92.0 & 8.0 \\
\hline 7 & $70 / \mathrm{F}$ & parasagittal & fibrous & I & 0.4 & normal & normal & 94.5 & 5.5 & 95.5 & 4.5 \\
\hline 8 & $75 / \mathrm{M}$ & falx & angio & I & 0.7 & normal & poly. & 75.5 & 24.5 & 55.0 & 45.0 \\
\hline 9 & $80 / \mathrm{F}$ & $\begin{array}{l}\text { tuberculum } \\
\text { sellae }\end{array}$ & men & I & 1.2 & normal & normal & 96.5 & 3.5 & 99.0 & 1.0 \\
\hline 10 & $70 / \mathrm{M}$ & tentorium & men & I & 2.5 & normal & normal & 94.5 & 5.5 & 99.0 & 1.0 \\
\hline 11 & $44 / \mathrm{M}$ & parasagittal & men & I & 1.0 & normal & normal & 96.0 & 4.0 & 95.5 & 5.0 \\
\hline 12 & $54 / \mathrm{F}$ & petroclival & men & I & 0.8 & normal & normal & 92.6 & 7.4 & 94.4 & 5.6 \\
\hline 13 & $41 / \mathrm{M}$ & convexity & men & I & 2.0 & normal & normal & 100.0 & 0 & 96.0 & 4.0 \\
\hline 14 & $45 / \mathrm{F}$ & parasagittal & fibrous & I & 0.4 & normal & normal & 94.7 & 5.3 & 85.0 & 15.0 \\
\hline 15 & $64 / \mathrm{F}$ & convexity & metapla & I & 0 & normal & normal & 87.0 & 13.0 & 99.0 & 1.0 \\
\hline 16 & $22 / F$ & convexity & trans & I & 7.8 & $\begin{array}{l}\text { def. } \\
\text { deletion }\end{array}$ & normal & 15.0 & 85.0 & 95.0 & 5.0 \\
\hline 17 & $56 / \mathrm{F}$ & tentorium & atyp & II & 8.2 & $\begin{array}{l}\text { dispro. } \\
\text { deletion }\end{array}$ & amp. & 3.6 & 96.4 & 9.4 & 90.6 \\
\hline 18 & $48 / \mathrm{F}$ & ventricle & atyp & II & 5.0 & $\begin{array}{l}\text { deletion } \\
\text { with imb. }\end{array}$ & amp. & 8.5 & 91.5 & 8.7 & 91.3 \\
\hline 19 & $62 / \mathrm{F}$ & convexity & atyp & II & 3.5 & $\begin{array}{l}\text { dispro. } \\
\text { deletion }\end{array}$ & normal & 7.8 & 92.2 & 63.8 & 36.2 \\
\hline 20 & $78 / \mathrm{M}$ & convexity & atyp & II & 6.3 & $\begin{array}{l}\text { def. } \\
\text { deletion }\end{array}$ & $\begin{array}{l}\text { def. } \\
\text { deletion }\end{array}$ & 15.0 & 84.5 & 16.7 & 83.3 \\
\hline 21 & $79 / F$ & convexity & atyp & II & 3.5 & $\begin{array}{l}\text { def. } \\
\text { deletion }\end{array}$ & imb. & 17.3 & 82.7 & 44.2 & 55.8 \\
\hline 22 & $55 / F$ & tentorium & atyp & II & 1.5 & $\begin{array}{l}\text { def. } \\
\text { deletion }\end{array}$ & normal & 14.0 & 86.0 & 63.0 & 37.0 \\
\hline 23 & $60 / \mathrm{F}$ & $\begin{array}{l}\text { sphenoid } \\
\text { ridge }\end{array}$ & atyp & II & 1.2 & $\begin{array}{l}\text { def. } \\
\text { deletion }\end{array}$ & normal & 24.1 & 75.9 & 57.5 & 42.5 \\
\hline
\end{tabular}

\section{Materials and Methods}

Tumor samples were collected from 16 consecutive surgically resected low-grade meningiomas, and 7 consecutive atypical meningiomas including 3 archival and 4 fresh samples obtained from 23 patients, 16 females and 7 males aged 22-80 years (mean 60.3 years). The locations of the tumors are shown in Table 1. All tumors were classified by histological examination and graded according to WHO guidelines. ${ }^{10)}$ The diagnostic criteria for atypical meningioma were based on increased mitotic activity defined as 4 or more mitoses per 10 high-power fields or 3 or more of increased cellularity, small cell with high nucleus/cytoplasm ratio, prominent nucleoli, uninterrupted patternless or sheet-like growth, and necrotic foci. ${ }^{10)}$

FISH analysis used a touch preparation of fresh samples. The material was prepared with Carnoy's fixation and denatured at $80^{\circ} \mathrm{C}$ for 5 minutes. Cell copy numbers were investigated by FISH using Vysis ${ }^{\circledR}$ LSI 1p36/1q25 and LSI 19q13/19p13 DualColor Probe (Abbott Laboratories, Abbott Park, Ill., U.S.A.). Signals were counted for each hybridization in randomly chosen regions of at least 200 nonoverlapping nuclei with intact morphology. Parallel touch preparation methods, prepared from the same surface as the hybridized slide, were used to confirm the successful collection of tumor cells. Parallel touch preparations for each tumor was stained with Papanicolaou stain and reviewed by a cytopathologist to identify the fraction of tumor cells. Tissues from archival samples were prepared as described before. ${ }^{12)}$

Assessment and interpretation of FISH results used the previously published criteria modified for 
Table 1, contd.

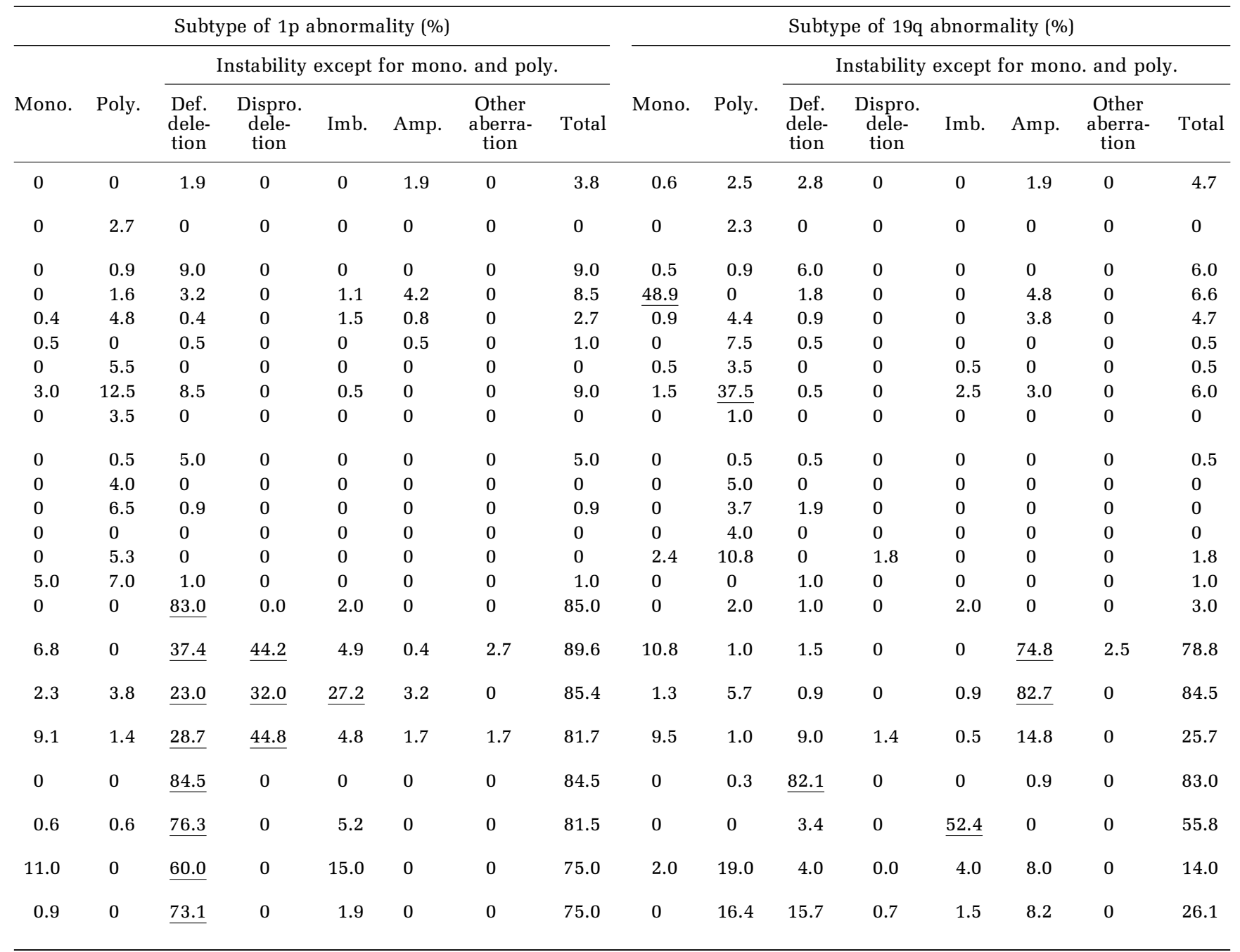

Abnormalities exceeding $20 \%$ are underlined. angio: angiomatous meningioma, amp: amplification, atyp: atypical meningioma, def.: definitive, dispro.: disproportional, fibrous: fibrous meningioma, FISH: fluorescent in situ hybridization, imb.: imbalance, LI: labeling index, men: meningothelial meningioma, metapla: metaplastic meningioma, mono.: monosomy, poly.: polysomy, trans: transitional meningioma, WHO: World Health Organization.

brain tumors (Table 2). ${ }^{12)}$ Deletion or imbalance was defined as alterations detected in $>20 \%$ of the nuclei. Comparison of intact nuclei from fresh cell preparations and truncated nuclei in paraffin sections showed that nuclear truncation resulted in approximately 5-9\% signal loss. ${ }^{1,4)}$ Nuclear truncation due to sectioning or other artifacts in the hybridization process could increase the false-positive signal deletion. Therefore, we adopted a cut-off value of $20 \%$ for FISH analysis. ${ }^{12)}$

All tumors were evaluated for the expression of proliferation-associated nuclear antigen Ki-67 (MIB-1) using formalin-fixed paraffin sections. Images captured with a digital camera were analyzed quantitatively with a free software package, Scion
Image (Scion Corporation, Frederick, Md., U.S.A.), to count the number of cells labeled with MIB-1. All results were reviewed by manual measurements to confirm this computer-assisted technique.

The relationships between $1 \mathrm{p} / 19 \mathrm{q}$ deletion or imbalance and histological grade were analyzed using the Fisher exact test. $P$ values of $<0.05$ were considered statistically significant. All samples were tested according to an institutional review board-approved protocol.

\section{Results}

The diagnoses and histological subtypes of the tumors are shown in Table 1. Table 1 also summa- 
Table 2 Definitions of chromosome status by fluorescence in situ hybridization (FISH)

\section{FISH-Chromosome 1 p36}

Deletion: one or less signal for chromosome 1 p36 (ratio 0/1, 0/2, $1 / 2,1 / 3,1 / 4$ etc.)

Definitive deletion: one or less signal for chromosome 1p36 in relation to normal reference probe signals on chromosome 1q25 (ratio $1 / 2,0 / 2$ )

Disproportional deletion: one or less signal for chromosome $1 \mathrm{p} 36$ with disproportion of the ratio of the reference probe (ratio 1/3, $1 / 4$ etc.)

Deletion with reference deletion: chromosome 1p36 deletion with deletion of reference region (ratio 0/1)

Imbalance: imbalance of the ratio of the reference probe to chromosome $1 \mathrm{p} 36$ with more than two reference probe signals (ratio $2 / 3,3 / 4,3 / 5$ etc.)

Polysomy: simultaneous increase of both signals (ratio $3 / 3,4 / 4$, $5 / 5$ etc.)

Monosomy: simultaneous decrease of both signals (ratio 1/1)

Amplification: target signal > reference signal per cell (ratio $3 / 2$ etc.)

Normal: no deletion, no imbalance and no polysomy detected by FISH with the probes used (ratio 2/2)
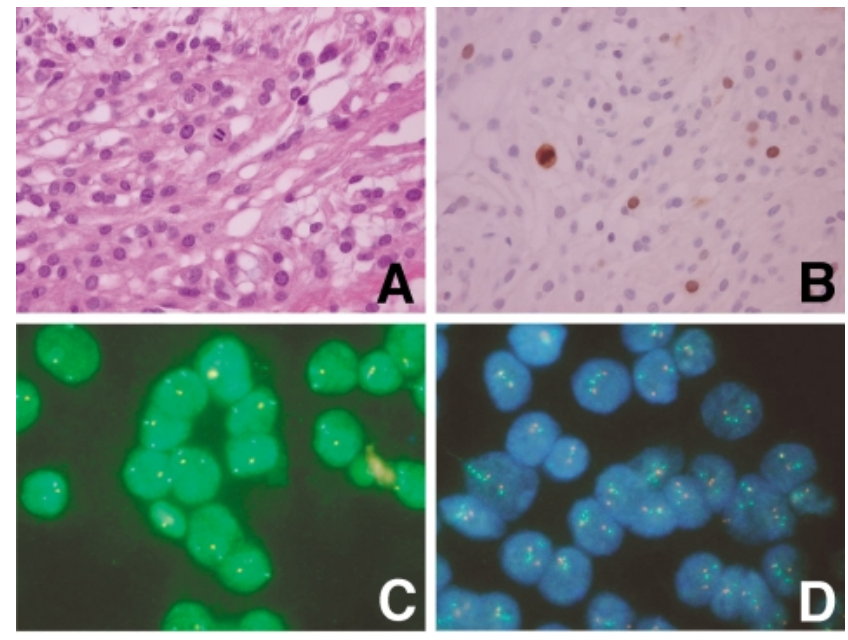

Fig. 1 A, B: Photomicrographs of samples of atypical meningioma showing uninterrupted patternless growth with mitotic figures (A: hematoxylin and eosin stain, original magnification $\times 400)$, and MIB-1 labeling showing active proliferation (B: immunohistochemistry for Ki-67, original magnification $\times 400)$. C, D: Fluorescent in situ hybridization analysis of chromosomal arms 1p/19q showing 1 p36 deletion status with a 2:1 ratio of control (green) signals and target (red) signals (C), and 19q13 imbalance status with 3:2 and 5:2 ratios of control (green) signals and target (red) signals (D).

rizes the genomic abnormalities of $1 \mathrm{p} / 19 \mathrm{q}$ status detected by FISH (Fig. 1) in the 23 tumors studied. The mean MIB-1 labeling index was not significantly higher for atypical meningiomas (mean $4.2 \%$ ) than for low-grade meningiomas (mean 1.3\%). All 7 atypical meningiomas showed chromosome $1 \mathrm{p}$ deletion including disproportional deletion and imbalance, and the cell population with $1 \mathrm{p}$ deletion accounted for over $50 \%$ of the tumor in all cases. In contrast, $1 p$ deletion was detected in only one of the 16 lowgrade meningiomas. Six of the 7 atypical meningiomas had $19 \mathrm{q}$ instability including deletion, imbalance, or amplification, whereas 2 of 16 low-grade meningiomas demonstrated 19q monosomy or polysomy (Table 1). These FISH analyses showed the genomic abnormalities of $1 p / 19 q$ status of atypical meningiomas were significantly different from those of low-grade meningioma $(p<0.05$ for both locations).

\section{Discussion}

FISH is a powerful tool for the assessment of target deoxyribonucleic acid dosages in interphase nuclei without paired blood samples and has been used for evaluating numerical and structural genomic aberrations in various tumors. ${ }^{5,12,13,17)}$ The primary advantages are applicability to archival, formalin-fixed paraffin-embedded material and morphological preservation, which is particularly attractive for studies on heterogeneous tissue samples without the need for microdissection. Detectable genomic alterations include deletion, imbalance, polysomy, translocation, and gene amplification. However, consensus criteria for assessment and interpretation of analytical results in brain tumors have not been established. ${ }^{12)}$ The present study used the criteria modified for brain tumors (Table 2). According to these criteria, "deletion" is defined as only one or less target signal $(1 / 2,1 / 3,1 / 4$ etc.) and subdivided into "definitive" deletion (1/2, 0/2), "disproportional" deletion (1/3, $1 / 4$ etc.), and deletion "with reference deletion" (0/1). "Imbalance" is defined as disproportion of the signal ratio $(2 / 3,3 / 4,3 / 5$ etc.). FISH is a sensitive method for evaluating numerical genomic abnormalities at the cytogenetic level. It is also important to distinguish "disproportional" deletion and imbalance from "definitive" deletion among these chromosomal instabilities.

The present study used FISH with chromosomespecific probes to evaluate $1 p$ and $19 q$ chromosome aberrations in low-grade and atypical meningiomas. Our results showed genomic abnormalities in the $1 p / 19 q$ status of atypical meningiomas, which were significantly different from the absence of abnormalities in low-grade meningioma. A few low-grade meningiomas showed abnormality of $1 \mathrm{p} / 19 \mathrm{q}$. Genetic changes associated with chromosome instability on chromosome $1 \mathrm{p}$ are important in both tumorigen- 
esis and tumor progression in meningiomas. Frequency of loss of heterozygosity $(\mathrm{LOH})$ on chromosome $1 p$ tends to increase with tumor grade, as $\mathrm{LOH}$ on $1 \mathrm{p}$ was observed in $40 \%$ of grade 2 meningiomas and $70 \%$ of grade 3 meningiomas. ${ }^{16)}$ Chromosome $22 \mathrm{q}$ deletion and/or mutation of neurofibromatosis type 2 gene (NF2) are most frequently detected as the earliest genetic aberrations and found in meningiomas of all malignancy grades, indicating that inactivation of this gene represents an early event in the pathogenesis of meningiomas. ${ }^{14,15,19,20)} \mathrm{LOH}$ for loci on chromosome 22q and mutations in the NF2 locus probably do not play a role in the development of malignancy in meningiomas. ${ }^{16)}$ Thus, the assessment of chromosome 22q is not suitable for the alterations associated with progression of meningiomas. $\mathrm{LOH}$ associated with meningioma progression has been extensively researched, ${ }^{2,16,18)}$ but only limited data on chromosomal aberrations by FISH are available. $3,6,13-15)$

FISH analysis should be assessed as numerical genomic abnormalities at the cytogenetic level, not as the rate of chromosome gain or loss. ${ }^{6,14,15)}$ Assessment of FISH deletion status is useful for the evaluation of chromosomal instability of meningiomas. The frequency of deletions is proportional to histological grade and chromosome $1 p$ deletion was identified in $23 \%$ of low-grade and $56 \%$ of atypical meningiomas. ${ }^{3)}$ Deletion of $1 \mathrm{p}$ occurred in $23-35 \%$ of low-grade meningiomas, and in $56-92 \%$ of the atypical meningiomas. ${ }^{3,13}$ However, these previous FISH studies did not discriminate between deletion and imbalance status.

The present study showed that FISH 1p/19q deletion/imbalance analysis is a sensitive method for detecting chromosome aberrations of meningiomas and provides useful information for the grading of meningiomas. Specific details relative to FISH deletion status were not provided in all previous reports, so the frequency of specific deletion types cannot be compared with the present results. However, our results indicate that the frequency of $1 \mathrm{p}$ deletion in low-grade meningiomas may be lower than previously reported and further investigation is needed. The present study also demonstrated that atypical meningiomas have chromosomal instability of $19 \mathrm{q}$ including deletion, imbalance, and amplification.

Previous FISH studies analyzing 1p status in brain tumors have not compared MIB-1 labeling index and the chromosomal state.3,6,13-15) The present results showed that MIB-1 labeling index is useful for grading meningiomas, but there is significant overlap. In contrast, FISH analysis of the $1 \mathrm{p} / 19 \mathrm{q}$ status clearly distinguished atypical meningioma from low-grade meningioma. The diagnosis of meningio- ma grade may depend on both assessment of proliferative state using MIB-1 labeling index and chromosomal state using FISH in the future.

In general, genetic changes precede morphological changes. Our results showed that a small group of low-grade meningiomas have $1 \mathrm{p} / 19 \mathrm{q}$ aberrations. Whether such chromosome instability is an indicator of biological aggressiveness in histologically benign subgroups of meningiomas is extremely interesting. Some authors reported that meningiomas with chromosome $1 \mathrm{p}$ loss show the higher rate of recurrence occurring independently from the histological classification. ${ }^{7-9)}$ In our series, some lowgrade meningiomas had FISH 1p definitive deletion and 19q monosomy or polysomy. Further investigation is needed to determine whether these low-grade meningiomas with chromosomal abnormality have high rates of recurrence and progression. Characterization of those genetic aberrations might facilitate the early identification of tumors with high intrinsic risk of progression. We plan to follow up patients with histologically benign meningiomas with a high percentage of $1 \mathrm{p} / 19 \mathrm{q}$ deletions or imbalance.

FISH 1p/19q deletion/imbalance analysis is a sensitive method for detecting chromosome aberrations in meningiomas and provides useful information for the grading of meningiomas. Assessment of both chromosomal state by FISH and proliferative state by MIB-1 labeling index might be important in the clinical management of meningiomas.

\section{References}

1) Aubele $M$, Zitzelsberger $H$, Szücs $S$, Werner $M$, Braselmann H, Hutzler P, Rodenacker K, Lehmann L, Minkus G, Höfler H: Comparative FISH analysis of numerical chromosome 7 abnormalities in 5-micron and 15-micron paraffin-embedded tissue sections from prostatic carcinoma. Histochem Cell Biol 107: 121-126, 1997

2) Bello MJ, de Campos JM, Kusak ME, Vaquero J, Sarasa JL, Pestana A, Rey JA: Allelic loss at $1 p$ is associated with tumor progression of meningiomas. Genes Chromosomes Cancer 9: 296-298, 1994

3) Cai DX, Banerjee R, Scheithauer BW, Lohse CM, Kleinschmidt-Demasters BK, Perry A: Chromosome 1p and 14q FISH analysis in clinicopathologic subsets of meningioma: diagnostic and prognostic implications. J Neuropathol Exp Neurol 60: 628-636, 2001

4) de Pender AM, Alers JC, Vissers KJ, de Both NJ, Dinjens WN, van Dekken H: Evaluation of oncogene amplification in intact and truncated cell nuclei of gastro-esophageal cancer cell lines by DNA in situ hybridisation. Acta Histochem 103: 127-138, 2001

5) Hashimoto N, Ichikawa D, Arakawa Y, Date K, Ueda S, Nakagawa Y, Horii A, Nakamura Y, Abe T, Inazawa J: Frequent deletions of material from chromo- 
some arm $1 p$ in oligodendroglial tumors revealed by double-target fluorescence in situ hybridization and microsatellite analysis. Genes Chromosomes Cancer 14: 295-300, 1995

6) Ishino S, Hashimoto N, Fushiki S, Date K, Mori T, Fujimoto M, Nakagawa Y, Ueda S, Abe T, Inazawa J: Loss of material from chromosome arm 1p during malignant progression of meningioma revealed by fluorescent in situ hybridization. Cancer 83: 360-366, 1998

7) Ketter R, Henn W, Niedermayer I, Steilen-Gimbel H, König J, Zang KD, Steudel WI: Predictive value of progression-associated chromosomal aberrations for the prognosis of meningiomas: a retrospective study of 198 cases. J Neurosurg 95: 601-607, 2001

8) Ketter R, Rahnenführer J, Henn W, Kim YJ, Feiden W, Steudel WI, Zang KD, Urbschat S: Correspondence of tumor localization with tumor recurrence and cytogenetic progression in meningiomas. Neurosurgery 62: 61-70, 2008

9) Ketter R, Urbschat S, Henn W, Feiden W, Beerenwinkel N, Lengauer T, Steudel WI, Zang KD, Rahnenführer J: Application of oncogenetic trees mixtures as a biostatistical model of the clonal cytogenetic evolution of meningiomas. Int J Cancer 121: 1473-1480, 2007

10) Kleihues P, Cavenee WK: World Health Organization Classification of Tumours of the Nervous System. Lyon, France, WHO/IARC, 2000, pp 176-184

11) Modha A, Gutin PH: Diagnosis and treatment of atypical and anaplastic meningiomas: a review. Neurosurgery 57: 538-550, 2005

12) Nagasaka T, Gunji M, Hosokai N, Hayashi K, Ikeda H, Ito M, Inao S: FISH 1p/19q deletion/imbalance for molecular subclassification of glioblastoma. Brain Tumor Pathol 24: 1-5, 2007

13) Pfisterer WK, Hank NC, Preul MC, Hendricks WP, Pueschel J, Coons SW, Scheck AC: Diagnostic and prognostic significance of genetic regional heterogeneity in meningiomas. Neuro Oncol 6: 290-299, 2004

14) Sayagues JM, Tabernero MD, Maillo A, Diaz P, Rasillo A, Bortoluci A, Gomez-Moreta J, Santos-Briz A, Morales F, Orfao A: Incidence of numerical chromosome aberrations in meningioma tumors as revealed by fluorescence in situ hybridization using 10 chromosome-specific probes. Cytometry 50: 153-159, 2002

15) Sayagues JM, Tabernero MD, Maillo A, Espinosa A, Rasillo A, Diaz P, Ciudad J, Lopez A, Merino M, Goncalves JM, Santos-Briz A, Morales F, Orfao A: Intratumoral patterns of clonal evolution in meningiomas as defined by multicolor interphase fluorescence in situ hybridization (FISH): is there a relationship between histopathologically benign and atypical/ anaplastic lesions? J Mol Diagn 6: 316-325, 2004

16) Simon M, von Deimling A, Larson JJ, Wellenreuther R, Kaskel P, Waha A, Warnick RE, Tew JM Jr, Menon AG: Allelic losses on chromosomes 14, 10, and 1 in atypical and malignant meningiomas: a genetic model of meningioma progression. Cancer Res 55: 4696-4701, 1995

17) Stock C, Ambros IM, Mann G, Gadner H, Amann G, Ambros PF: Detection of Ip36 deletions in paraffin sections of neuroblastoma tissues. Genes Chromosomes Cancer 6: 1-9, 1993

18) Sulman EP, Dumanski JP, White PS, Zhao H, Maris JM, Mathiesen T, Bruder C, Cnaan A, Brodeur GM: Identification of a consistent region of allelic loss on 1 p32 in meningiomas: correlation with increased morbidity. Cancer Res 58: 3226-3230, 1998

19) Wada K, Maruno M, Suzuki T, Kagawa N, Hashiba T, Fujimoto Y, Hashimoto N, Izumoto S, Yoshimine T: Chromosomal and genetic aberrations differ with meningioma subtype. Brain Tumor Pathol 21: 127-133, 2004

20) Weber RG, Bostrom J, Wolter M, Baudis M, Collins VP, Reifenberger G, Lichter P: Analysis of genomic alterations in benign, atypical, and anaplastic meningiomas: toward a genetic model of meningioma progression. Proc Natl Acad Sci U S A 94: 1471914724, 1997

Address reprint requests to: Toru Nagasaka, M.D., Department of Neurosurgery, Japanese Red Cross Nagoya Daiichi Hospital, 3-35 Michishita-cho, Nakamuraku, Nagoya 453-8511, Japan.

e-mail: toru-ngy@umin.ac.jp

\section{Commentary}

Meningiomas are the second most common primary tumor of the central nervous system. Atypical (grade II) and anaplastic/malignant (grade III) meningiomas, which are associated with a higher rate of recurrence and aggressive growth, account for about $10 \%$ of all meningiomas. To find certain sensible and reliable indicators for grading of meningioma is crucial and valuable. The genetic aspects of meningiomas have been studied intensively during the past decade. Chromosome 22q, 1p, 9q, 14q and 10q aberration have been detected to correlate with meningioma progression. In the present article, the authors conclude that FISH 1p/19q deletion/imbalance analysis is a sensitive method for detecting chromosome aberrations of meningiomas and provides useful information for the grading of meningioma. Chromosome 1p/19q loss of heterozygosity has been regarded as a molecular genetic characteristic for oligodendroglioma. Can $1 p / 19 q$ deletion/imbalance be an indicator for meningioma grading, treatment choice and prognosis expectation? The authors have made a valuable contribution. To answer this question finally, more larger studies are expected in the future and the $1 \mathrm{p} / 19 q$ status in anaplastic meningioma needs further investigation.

Shengde BAO, M.D.

Professor and Chairman

Department of Neurosurgery

Peking University First Hospital

Beijing, P.R.C. 